\title{
Original article (short paper) \\ Movement patterns during the process of standing up in children with spastic diplegia
}

\author{
Elisabete Martins \\ Alcoitão School of Health, Portugal \\ Jorge Fernandes \\ Ana Cruz-Ferreira \\ University of Évora, Évora, Portugal
}

\begin{abstract}
The analysis of the movement patterns of children with spastic diplegia (SD) during the process of standing up can contribute to a better understanding of postural control. The purpose of this study was to describe the movement patterns during this task in children with SD and typical development and to analyze the differences according to their age group. Participated 40 children (38-154 months), 20 children with SD and 20 children with typical development. The participants were instructed to lie down in a supine position and quickly stand up (10 trials). Motor task sessions were videotaped and subsequently analyzed. Children with SD had more asymmetrical and less efficient movement patterns in the Upper Limbs (UL), Axial Region (AR) and Lower Limbs (LL). The oldest group of children with SD did not have more mature and efficient movement patterns, and the oldest children with typical development have more mature and efficient movement patterns in the UL and AR.
\end{abstract}

Keywords: spastic diplegia, motor patterns, postural control

Resumo - "Padrões de movimento durante o processo de levantar em crianças com diplegia espástica." A análise dos padrões de movimento de crianças com diplegia espástica (DE) durante o movimento de levantar pode contribuir para uma melhor compreensão do controle postural. O objetivo do estudo foi descrever os padrões de movimento durante esta tarefa em crianças com DE e com desenvolvimento típico e analisar as diferenças de acordo com a idade. Participaram 40 crianças (38-154 meses), 20 crianças com DE e 20 crianças com desenvolvimento típico. Os participantes foram instruídos para se deitarem em posição de decúbito dorsal e levantarem-se rapidamente (10 tentativas). As sessões foram gravadas e analisadas posteriormente. As crianças com DE apresentaram padrões de movimentos mais assimétricos e menos eficientes nos Membros Superiores (MS), Região Axial (RA) e Membros Inferiores (MI). As crianças mais velhas com DE não apresentaram padrões de movimento mais maduros e eficientes, e as mais velhas com desenvolvimento típico apresentaram padrões movimentos mais eficientes e maduros nos MS e RA.

Palavras-chave: diplegia espástica, padrões motores, controle postural

Resumen - "Patrones de movimiento durante el proceso de levantar en niños con diplejía espástica." El análisis de los patrones de movimiento de los niños con diplejía espástica (DE) durante el movimiento de levantar puede contribuir para una mejor comprensión del control postural. El objetivo del estudio fue describir los patrones de movimiento durante esta tarea en niños con DE y con desarrollo típico y analizar las diferencias en función de la edad. Participaron 40 niños (38-154 meses), 20 niños con DE y 20 niños con desarrollo típico. Los participantes fueron instruidos para que se echaran en decúbito dorsal y se levantaran rápidamente (10 intentos). Las sesiones fueron gravadas y analizadas posteriormente. Los niños con DE presentaron patrones de movimientos más asimétricos y menos eficientes en los miembros superiores (MS), región axial (RA) y miembros inferiores (MI). Los niños más viejos con DE no mostraron patrones de movimiento más eficientes y maduros, y los más viejos con desarrollo típico mostraron patrones de movimientos más eficientes y maduros en los MS y RA.

Palabras claves: diplejía espástica, patrones motrices, control postural

\section{Introduction}

The term cerebral palsy refers to a range of clinical symptoms, with related service requirements, resulting from lesions or abnormalities in the brain that develop early in life (Bax et al., 2005). From a motor control perspective, cerebral palsy can be characterized as a group of movement disorders with various types of motor dysfunction (Parker, Carriere, \& Habesttuit, 1993; Woollacott \& Shumway-Cook, 2005). Movement and posture are affected in cerebral palsy patients (Burtner, Woollacott, Craft, \& Roncesvalles, 2007; Ferdjallah, Harris, Smith, \& Wertsch, 2002), with a limited ability to adjust 
postural activity to task-specific circumstances (Ju, Hwang, \& Cherng, 2012; Van der Heide et al., 2004). Massion (1992) inferred that there are two main causes for these movement disorders: dysfunction of the postural networks processing for anticipatory adjustments and a dysfunction of the premotor areas responsible for gating the learned circuits, which provide the appropriate postural adjustment for a specific motor act. Additionally, children with cerebral palsy have smaller and weaker muscles (Elder et al., 2003; Malaiya et al., 2007) with reduced motor control (Bax et al., 2005). Several studies have determined that muscle weakness affects walking ability and other motor functions (Eek, Tranberg, Zügner, Alkema, \& Beckung, 2008; Ibrahim, Eid, \& Moawd, 2014) and that strength training improved basic motor abilities, functional muscle strength, and walking efficiency in children with cerebral palsy (Liao, Liu, Liu, \& Lin, 2007; Scholtes et al., 2012; Thompson, Stebbins, Seniorou, \& Newham, 2011).

Children with spastic diplegia (SD), the most prevalent type of cerebral palsy, had insufficient postural control ability (Ju et al., 2012) and altered motor functions, which are evident during various tasks, such as posture and walking (Fedrizzi et al., 2000; Rosenbaum, Paneth, Leviton, Goldstein, \& Bax, 2007). These children have lower limb weakness and muscle imbalance across joints with minor motor deficits in the upper limbs, but most are able to walk independently (Yokochi, 2001) with difficulty in cadence and walking speed (Bell, Õnpuu, de Luca, \& Romness, 2002).

One of the earliest signs of SD is the delayed acquisition of the righting function of the head, which ensures control of head posture and movement along and around the body axis (Dan et al., 2000; Lin, 2003). These studies indicate that whole-body movements involving changes in posture can help identify specific strategies for motor control in SD. Two additional studies have investigated these strategies in hemiplegic children (Mewasingh et al., 2004; Hadders-Hagra, Van Der Fitts, Stremmelaar, \& Touwen, 1999). The observation of movement patterns during the process of standing up can contribute to a better understanding of dynamic postural control and can be used in experimental studies.

The movement patterns observed during the process of standing up from a supine position in children with typical motor development has been analyzed using a multi-segmental approach that evaluates three body regions: upper limbs - UL, axial region - AR, and lower limbs - LL (Marsala \& VanSant, 1998; VanSant, 1988a, 1988b). The values of these segmental scores may reflect the developmental age of the child, with higher scores obtained by older children, corresponding to more symmetrical movement. Marsala and VanSant (1998) designed a study to describe age-related differences in motor performance during rising in sixty toddlers that were divided into three age groups (15-25 months, 26-36 months, and 37-47 months). The authors determined that the most common UL pattern for all three age groups were "push and reach to bilateral push;" the pattern "push and reach" were observed more frequently in the two older groups compared with the youngest group; a small percentage of the two older groups also used the "push and reach to bilateral push followed by pushing on leg" and "push and reach followed by pushing on leg." The two most common AR patterns for the two youngest groups were "full rotation, abdomen up" and "full rotation, abdomen down;" in the oldest group "full rotation, abdomen up" were the most prevalent pattern; a small percentage of the two older groups also used the "partial rotation" and the smallest percentage used the "forward with rotation" pattern. For the LL component, the most prevalent pattern in the youngest group was the "pike" pattern; the "kneel" pattern was most common in the middle age group; the "half kneel" pattern was most common in the oldest group; the patterns of "pike" and "pike-jump to squat" were observed in a small percentage of trials across the three groups; the "asymmetrical/ wide-based squat" pattern was noted in a few trials in the two older groups.

This study also demonstrated that the movements of toddlers during the process of standing up were accurately described in a study performed by VanSant (1988b), which examined one hundred twenty children aged between 48 and 84 months. Another study by this author determined that the righting movements assume a mature form during later childhood and the adult years: for the UL component, a symmetrical pushing pattern was most common; the most frequently observed action of the AR component was symmetrical flexion followed by extension; and the LL component most commonly demonstrated an asymmetrical squatting pattern (VanSant, 1988a).

Mewasingh et al. (2002) analyzed whether children with $\mathrm{SD}$, aged between 60 and 132 months, used the same UL, AR, and LL patterns from the repertoire described for unimpaired children. The authors determined that children with spastic diplegia used movement patterns described in normal children, but with tendency for more asymmetric patterns. For the UL pattern, the SD children often used the "push and reach to bilateral push" and "push and reach" patterns. For the AR patterns, none of the patterns observed were symmetric. For the LL pattern, the strategies preferentially used by SD children were the "half-kneel" and "asymmetrical wide-based squat" patterns. Therefore, a component model analysis would increase the information available to physical education and physical therapy professionals to plan intervention and management programs for children with cerebral palsy. However, it will be important to analyze these patterns within different age groups of this population.

The purpose of our study was to describe the movement patterns during a rise from the supine position to the standing position that are used by children with SD and with typical motor development and to analyze the differences according their age groups (38-79 and 80-154 months). The youngest group was included at the fundamental movement stage, which is important for efficient and more complex movements. The older group was included at the specialized movement stage, which expresses more refined and efficient movements.

This study tested the hypothesis that the movement patterns of the three body regions (UL, AR, and LL) during the process of standing up from a supine position are different, more asymmetric, and less efficient in children with SD compared with unimpaired children and also vary with age. 


\section{Methods}

\section{Participants}

Forty participants aged between 38 and 154 months participated in this study. The sample included 20 participants $(6$ females and 14 males) with SD (Experimental Group - EG) and 20 (12 females and 8 males) with typical motor development (Control Group - CG).

The EG was comprised of all the SD participants, who attend physical therapy, occupational therapy and speech therapy at the Rehabilitation Cerebral Palsy Center of Calouste Gulbenkian, in Lisbon-Portugal. Only two participants were born at term. This group was divided according to their age: 3 females and 6 males were aged between 38 and 79 months $\left(\mathrm{EGa}_{1}, n=9 ; 57.44 \pm 15.51\right)$ and 3 females and 8 males were aged between 80 and 154 months $\left(\mathrm{EGa}_{2}\right.$, $n=11 ; 117.45 .5 \pm 24.09$ ). All participants had level I according to the Gross Motor Function Measure System - GMFMS (Palisano et al., 2000; Silva, Pfeifer, \& Funayama, 2013). This inclusion criterion allowed the completion of the motor tasks required in the study.

The CG consisted of 20 age-matched participants with typical motor development that had a gestational age between 38 and 42 weeks, which were recruited from the families of the SD participants. Convenience sampling was used to identify equal numbers of participants by age between the EG and CG. The CG was divided into one subgroup ( 5 females and 4 males) that were aged between 38 and 79 months ( $\left.\mathrm{CGa}_{1}, n=9 ; 57.56 \pm 16.27\right)$, which were included in the acquisition phase of fundamental motor skills, and the other subgroup (7 females and 4 males) aged between 80 and 154 months $\left(\mathrm{CGa}_{2}, n=11 ; 117.09 \pm 22.53\right)$, which were included in the acquisition phase of specialized motor skills (Gallahue \& Ozmun, 2005).

All parents accepted the participation of their children in this study and signed an informed consent form. This study was approved by the Ethics in Research Committee of the University of Évora ( $\left.n^{\circ} 08010\right)$.

\section{Measurements}

The participants were instructed to lie in a supine position on a rubber mat ( $3 \mathrm{~m} \times 2 \mathrm{~m} \times 8 \mathrm{~mm})$ and quickly stand up. Simple verbal instructions for this motor task were provided and there was no prior demonstration. Each participant performed ten trials at an interval of a few seconds between each trial. The motor task sessions were videotaped using a high speed VHS video camcorder (Sony Hi 8). The tripod-mounted video camera was placed $2 \mathrm{~m}$ on a perpendicular line from the participant and $80 \mathrm{~cm}$ above the floor. To ensure a full view of the participants, the zoom function was used. The filming sessions occurred at same hour of the day, in the same place and were viewed twice. Two physiotherapist observers, with experience working with SD children, performed the movement sessions and analyzed the videotapes. The movements of the UL, AR, and LL patterns were evaluated using a segmental scale of movement pattern categories (Marsala \& VanSant, 1998; VanSant, 1988a, 1988b). For the UL, AR, and LL patterns, the possible scores ranged from 1 to 6,1 to 5 , and 1 to 7 , respectively (Table 1). To minimize bias, the classification of the movement patterns was performed in the following sequence: the first viewing evaluated the UL pattern, the second the AR pattern and the last viewing evaluated the LL movement pattern. Increased scores corresponded to a more efficient movement (Marsala \& VanSant, 1998; VanSant, 1988b). The mean segmental score according to the number of trials per child was used for statistical analyzes. A total of 1200 trials were analyzed.

The analyses of the movement patterns by two observers enabled the estimation of the inter-observer agreement. One observer analyzed the movement patterns twice, 2 weeks apart, to estimate intra-observer agreement. The agreement within first and second observations of one observer and between the two observers was $100 \%$ for all analyzed patterns, with exception of the LL patterns in the EG, which was $80 \%$. The Kappa values of the LL patterns in the EG was 0.76 and 1 for the other patterns of the two groups (EG and CG). These results show excellent inter- and intra-observer agreement, assuring confidence and reproducibility during the use of this segmental scale of movements.

Table 1. Movement patterns during a rise from the supine position to the standing position.

\begin{tabular}{|c|c|c|}
\hline \multicolumn{2}{|c|}{ Movement patterns } & \multirow{2}{*}{$\begin{array}{c}\begin{array}{c}\text { Segmental } \\
\text { Score }\end{array} \\
1\end{array}$} \\
\hline \multirow{6}{*}{$\mathbf{U L}$} & Push and reach to bilateral push & \\
\hline & Push and reach - asymmetric push & 2 \\
\hline & Symmetric push & 3 \\
\hline & Symmetric reach & 4 \\
\hline & Push and reach followed by pushing on leg & 5 \\
\hline & $\begin{array}{l}\text { Push and reach to bilateral push followed } \\
\text { by pushing on leg }\end{array}$ & 6 \\
\hline \multirow{5}{*}{$\mathbf{A X}$} & Full rotation abdomen down & 1 \\
\hline & Full rotation abdomen up & 2 \\
\hline & Partial rotation & 3 \\
\hline & Forward with rotation & 4 \\
\hline & Symmetric & 5 \\
\hline \multirow{7}{*}{$\mathbf{L L}$} & Pike & 1 \\
\hline & Pike - Jump to squat & 2 \\
\hline & Kneel & 3 \\
\hline & Jump to squat & 4 \\
\hline & Half-Kneel & 5 \\
\hline & Asymmetric / wide based squat & 6 \\
\hline & Narrow - based symmetric squat & 7 \\
\hline
\end{tabular}

\section{Statistical analysis}

All statistical analyzes were computed using PASWStatistics 18.0 (SPSS Inc. Chicago, IL). The statistically significant $p$ value was set at .05 for all study analyzes. According to the results from the test for normality (ShapiroWilkes) and test for homoscedasticity (Levene), Student's 
$t$-test or the Mann-Whitney test were used to compare the groups in the study.

\section{Results}

\section{UL movement patterns according age and group}

As shown in Table 2, the EG at the UL level only used the two more asymmetric movement patterns. Conversely, the CG predominantly used the more symmetrical and efficient patterns. The UL patterns more frequently observed in the EG were "push and reach to bilateral push" (52.2\%) in youngest age group and "push and reach-asymmetric push" (50.9\%) in older group. The most frequent pattern in the CG was $71.1 \%$ "symmetric push" in the youngest group and 53.6\% "symmetric reach" in the older group. These results indicate that the EG and CG used different motor strategies.

The inter-group analysis revealed significant differences between the UL patterns of the EG and $\mathrm{CG}\left(\mathrm{EGa}_{1} / \mathrm{CGa}_{1}\right.$ and $\left.\mathrm{EGa}_{2} / \mathrm{CGa}_{2}\right)$ in each age subgroup $\left(\mathrm{a}_{1}, p<.05 ; \mathrm{a}_{2}, p<.001\right)$, where the $\mathrm{CG}$ tended to use more symmetrical and efficient patterns.

The intra-group analysis results demonstrated that the youngest and oldest participants of the EG used the same patterns of movement $(p>.05)$. Furthermore, there were differences between the $C G$ age subgroups, where the oldest subgroup had a significant tendency $(p<.05)$ to use more efficient patterns. Table 3 shows the intra and inter-group analysis of the segmental scores of the UL, AR, and LL movement patterns.

\section{AR patterns according age and group}

At the AX level, the EG preferentially used rotational movements and the CG used more efficient and symmetric patterns. The youngest participants of the EG often used the "partial rotation" (60\%) and "forward with rotation" $(40 \%)$ patterns, while the oldest age subgroup used the "forward with rotation" (35.5\%) and "partial rotation" $(25.5 \%)$ patterns but also the two less efficient patterns (Table 2). The youngest CG participants, as well, used the "forward with rotation" pattern in $60 \%$ of trials and the oldest age subgroup preferentially used the "symmetric" pattern ( $71.8 \%$, Table 2$)$.

The significant differences between the AR patterns of both groups in each age subgroup (inter-group: $\mathrm{EGa}_{1} / \mathrm{CGa}_{1}$ and $\mathrm{EGa}_{2} /$ $\mathrm{CGa}_{2}$ ) determined that these groups are two distinct populations $\left(\mathrm{a}_{1}, p<.05 ; \mathrm{a}_{2}, p<.001\right)$, where the CG tended to use more efficient patterns (Table 3 ).

The intra-group analysis within the EG did not demonstrate a significant tendency toward the use of more efficient patterns $\left(\mathrm{EGa}_{1} / \mathrm{EGa}_{2}, p>.05\right)$ because this group used the patterns that required more rotational movement. The CG demonstrated a significant tendency $\left(\mathrm{CGa}_{1} / \mathrm{CGa}_{2}, p<.01\right)$ towards using more efficient and symmetric patterns in the oldest subgroup (Table 3 ).

Table 2. Incidence of each movement pattern in each age group expressed as percentage of trials ${ }^{\#}$

\begin{tabular}{|c|c|c|c|c|c|}
\hline \multicolumn{2}{|c|}{ Movement Patterns } & \multirow{2}{*}{$\begin{array}{c}\text { EGa1 } \\
47(52.2 \%)\end{array}$} & \multirow{2}{*}{$\frac{\text { EGa2 }}{54(49.1 \%)}$} & \multirow[t]{2}{*}{ CGa1 } & \multirow[t]{2}{*}{ CGa2 } \\
\hline \multirow{6}{*}{ UL } & Push and reach to bilateral push & & & & \\
\hline & Push and reach - asymmetric push & $43(47.8 \%)$ & $56(50.9 \%)$ & $6(6.7 \%)$ & \\
\hline & Symmetric push & & & $64(71.1 \%)$ & $31(28.2 \%)$ \\
\hline & Symmetric reach & & & $14(15.6 \%)$ & $59(53.6 \%)$ \\
\hline & Push and reach followed by pushing on leg & & & $1(1.1 \%)$ & $15(13.6 \%)$ \\
\hline & Push and reach to bilateral push followed by pushing on leg & & & $5(5.6 \%)$ & $5(4.5 \%)$ \\
\hline \multirow{5}{*}{$\mathbf{A X}$} & Full rotation abdomen down & & $16(14.5 \%)$ & & \\
\hline & Full rotation abdomen up & & $27(24.5 \%)$ & & \\
\hline & Partial rotation & $54(60 \%)$ & $28(25.5 \%)$ & $21(23.3 \%)$ & \\
\hline & Forward with rotation & $36(40 \%)$ & $39(35.5 \%)$ & $54(60 \%)$ & $31(28.2 \%)$ \\
\hline & Symmetric & & & $15(16.7 \%)$ & $79(71.8 \%)$ \\
\hline \multirow{7}{*}{$\mathbf{L L}$} & Pike & & & & \\
\hline & Pike- Jump to squat & & & & \\
\hline & Kneel & $32(35.5 \%)$ & $58(52.7 \%)$ & $5(5.6 \%)$ & \\
\hline & Jump to squat & $37(41.1 \%)$ & $12(10.9 \%)$ & $2(2.2 \%)$ & \\
\hline & Half-Kneel & $11(12.2 \%)$ & $3(2.7 \%)$ & $44(48.9 \%)$ & $26(23.6 \%)$ \\
\hline & Asymmetric / wide based squat & $10(11.1 \%)$ & $23(20.9 \%)$ & $30(33.3 \%)$ & $54(49.1 \%)$ \\
\hline & Narrow - based symmetric squat & & $14(12.7 \%)$ & $9(19 \%)$ & $30(27.3 \%)$ \\
\hline
\end{tabular}

"EGa1, 90 trials; EGa2, 110 trials; CGa1, 90 trials; CGa2 110 trials.

\section{LL patterns according age and group}

The LL patterns most frequently used by the youngest EG participants were the "kneel" (35.5\%) and "jump to squat"
(41.1\%) patterns and the oldest subgroup preferentially used the "kneel" (52.7\%) pattern, which confirmed that these age groups used the same modal patterns. The youngest CG participants tended to use more elaborated patterns than the EG, more often 
using the "half-kneel" (48.9\%) and "asymmetric/wide based squat" (33.3\%) patterns. Similarly, the oldest CG participants exhibited the same tendency with $49.1 \%$ using the "asymmetric/ wide based squat", $27.3 \%$ the "narrow-based symmetric squat", and $23.6 \%$ the "half-kneel" patterns (Table 2).

The inter-group analysis $\left(\mathrm{EGa}_{1} / \mathrm{CGa}_{1}\right.$ and $\left.\mathrm{EGa}_{2} / \mathrm{CGa}_{2}\right)$ revealed significant differences between groups $\left(\mathrm{a}_{1}, p<.001 ; \mathrm{a}_{2}\right.$, $p<.01$ ), where the CG tended to use more efficient patterns (Table 3).

The intra-group analysis demonstrated that there were no significant differences between the $\mathrm{EG}$ and between the $\mathrm{CG}$ age subgroups. The EG use the same patterns (EGa1/EGa2, $p>.05$ ) that required kneel and jump to squat patterns, and CG used the same patterns (CGa1/CGa2, $p>.05)$ that required half-kneel and wide based squat patterns (Table 3 ).

Table 3. Differences in the segmental scores of movement patterns (UL, AX, LL) between the intra and inter-groups.

\begin{tabular}{|c|c|c|c|c|}
\hline \multicolumn{2}{|c|}{ Movement Patterns } & Groups & Mean \pm SD & $p$ values \\
\hline \multirow{6}{*}{ UL } & \multirow{2}{*}{ Inter-group } & EGa1 & $1.47 \pm 0.46$ & \multirow[t]{2}{*}{$.021 \#$} \\
\hline & & CGa1 & $2.27 \pm 0.66$ & \\
\hline & \multirow{4}{*}{ Intra-group } & $\mathrm{EGa} 2$ & $1.50 \pm 0.45$ & \multirow[t]{2}{*}{$.000 \#$} \\
\hline & & CGa2 & $2.94 \pm 0.76$ & \\
\hline & & EGal & $1.47 \pm 0.46$ & \multirow[t]{2}{*}{$.813 \#$} \\
\hline & & $\mathrm{EGa} 2$ & $1.50 \pm 0.45$ & \\
\hline \multirow{8}{*}{$\mathbf{A X}$} & \multirow{5}{*}{ Inter-group } & CGa1 & $2.27 \pm 0.66$ & \multirow[t]{2}{*}{$.030 \#$} \\
\hline & & $\mathrm{CGa} 2$ & $2.94 \pm 0.76$ & \\
\hline & & EGa1 & $3.40 \pm 0.46$ & \multirow[t]{2}{*}{$.040 \#$} \\
\hline & & CGa1 & $3.93 \pm 0.55$ & \\
\hline & & $\mathrm{EGa} 2$ & $2.81 \pm 1.02$ & \multirow[t]{2}{*}{$.000 \#$} \\
\hline & \multirow{3}{*}{ Intra-group } & $\mathrm{CGa} 2$ & $4.71 \pm 0.39$ & \\
\hline & & EGa1 & $3.40 \pm 0.46$ & \multirow[t]{2}{*}{$.132 \#$} \\
\hline & & $\mathrm{EGa} 2$ & $2.81 \pm 1.02$ & \\
\hline \multirow{10}{*}{$\mathbf{L L}$} & \multirow{6}{*}{ Inter-group } & CGa1 & $3.93 \pm 0.55$ & \multirow[t]{2}{*}{$.005 \#$} \\
\hline & & $\mathrm{CGa} 2$ & $4.71 \pm 0.39$ & \\
\hline & & EGa1 & $3.76 \pm 0.61$ & \multirow[t]{2}{*}{$.000 \dagger$} \\
\hline & & CGal & $5.40 \pm 0.71$ & \\
\hline & & $\mathrm{EGa} 2$ & $3.66 \pm 1.16$ & \multirow[t]{2}{*}{$.001 \#$} \\
\hline & & $\mathrm{CGa} 2$ & $6.03 \pm 0.45$ & \\
\hline & \multirow{4}{*}{ Intra-group } & EGal & $3.76 \pm 0.61$ & \multirow[t]{2}{*}{$.172 \#$} \\
\hline & & $\mathrm{EGa} 2$ & $3.66 \pm 1.16$ & \\
\hline & & CGal & $5.40 \pm 0.71$ & \multirow[t]{2}{*}{$056 \dagger$} \\
\hline & & $\mathrm{CGa} 2$ & $6.03 \pm 0.67$ & \\
\hline
\end{tabular}

${ }^{*} p$ value of $\mathrm{U}$ Mann-Whitney. ${ }^{\dagger} p$ value of Student's $t$-test.

\section{Discussion}

The children with SD used predominantly more asymmetrical and less efficient movement patterns during the process of standing up from a supine position, without alterations in the advanced age group. Meanwhile, the unimpaired children used more symmetrical and efficient patterns, with increased symmetry in the advanced age group. Additionally, all the segmental movement patterns of both groups were identified according to the patterns described in other studies (Marsala \& VanSant, 1998; VanSant, 1988a, 1988b), except for one stereotypical LL pattern observed in one subject with SD.
The children with SD stood up from a supine position using mostly basic patterns of movement, including those described in studies examining normal toddlers (Marsala \& VanSant, 1998). The children's UL patterns only used the two more basic and asymmetrical patterns. Similarly, one study examining children with hemiplegia demonstrated that these children used a more asymmetrical pattern compared with their normally developed peers (Mewasingh et al., 2004). The motor action of standing up involves the projection of the body center of gravity inside the supporting surface. The increased maturation in the neural and musculoskeletal systems associated with experience reflects muscular control against gravity, which compensates the displacement of the center of gravity caused by the moving segments (Massion, 1998). In SD patients, periventricular lesions disrupt the inter-neural circuits that determine the central constraints and consequently affect the patient's ability to adjust their postural activity to this task (Ju et al., 2012). These studies clarify our results that revealed the tendency of unimpaired children to use more symmetric patterns, which require predominantly anterior-posterior weight transfer, and that SD children use more rotational and asymmetric AR and LL movements.

Children with SD adopted a more global flexor posture and immature movement pattern than their normally developed peers in all age subgroups during this motor task. There were more mature movement patterns in the UL and AR in the group of oldest unimpaired children, but this maturity was not evident in the LL movement patterns or in three body regions in the SD group. These results indicate that the motor strategies used by the oldest unimpaired children had increased efficiency, although SD children did not have this behavior with advanced age. Some authors unanimously believe that the neural and muscular constraints in cerebral palsy patients are responsible for inhibiting the motor control process and, subsequently, later motor abilities, such as standing up from a supine position (Mewasingh et al., 2002, 2004). It is plausible that the variability of movement acquired by the neural networks and the subsequent development occurs through the experience gained during the most functional movement patterns. Therefore, abnormal motor development due to brain lesions at an early developmental stage is characterized by a limited repertoire of motor strategies and, subsequently, less efficient movement strategies during the patient's life span (Mewasingh et al., 2004).

The prevalence of asymmetric movements in the older SD age group, in contrast to the motor sequential strategies of the older unimpaired children, can be explained by the impairment of the developing central nervous system during cerebral palsy (Rosenbaum et al., 2007). The presence of the neural and muscular constraints that affect muscular weakness could be responsible for the limited and restricted repertoire of movements necessary for the control of different motor functions demonstrated by SD children (Eek et al., 2008; Ibrahim et al., 2014; Woollacott \& Shumway-Cook, 2005).

The relationship among the sequences of these body regions was not objective of this study, but it is important to characterize this relationship in future studies. Foremost, it would be important analyze the relationships between lower-extremity spasticity (passive spasticity test), strength 
(isokinetic dynamometer), and the patterns of movement during the process of standing up.

The principal limitation of this study was the limited sample size because a larger sample size would have allowed the analysis of the UL, AR and LL patterns of children with Gross Motor Function Classification System (GMFCS) level II for comparisons with children with GMFCS I.

\section{Conclusion}

The study provides evidence that children with SD during the process of standing up from a supine position used the same general patterns of movement observed in unimpaired children. However, in the SD children, the movement patterns of the three body regions (UL, AR, and LL) were more restricted and asymmetrical, as expressed by a limited and less efficient movement repertoire.

The oldest group of children with SD did not have more mature and efficient movement patterns in the UL, AR, and LL and the oldest unimpaired children only had more efficient and mature movement in the UL and AR patterns relative to the younger age groups.

The analysis of the movement patterns during the process of standing up from a supine position characterizes the limited repertoire of movement in SD children at specific ages and contributes to a better understanding of their motor and postural control.

\section{References}

Bax, M., Goldstein, M., Rosenbaum, P., Leviton, A., Paneth, N., Dan, B., ... Damiano, D. (2005). Proposed definition and classification of cerebral palsy. Developmental Medicine \& Child Neurology, 47, 571-576. doi:10.1017/s001216220500112x

Bell, K., Õunpuu, S., DeLuca, P., \& Romness, M. (2002). Natural Progression of Gait in Children With Cerebral Palsy. Journal of Pediatric Orthopaedics, 22, 677-682. doi:10.1097/01241398-200209000-00020

Burtner, P., Woollacott, M., Craft, G., \& Roncesvalles, M. (2007). The capacity to adapt to changing balance threats: A comparison of children with cerebral palsy and typically developing children. Developmental Neurorehabilitation, 10, 249-260. doi:10.1080/17518420701303066

Dan, B., Bouillot, E., Bengoetxea, A., Noël, P., Kahn, A., \& Cheron, G. (2000). Head stability during whole body movements in spastic diplegia. Brain and Development, 22, 99-101. doi:10.1016/ s0387-7604(99)00123-0

Eek, M.N., Tranberg, R., Zügner, R., Alkema, K., \& Beckung, E. (2008). Muscle strength training to improve gait function in children with cerebral palsy. Developmental Medicine \& Child Neurology, 50, 759-764. doi:10.1111/j.1469-8749.2008.03045.x

Elder, G., Kirk, J., Stewart, G., Cook, K., Weir, D., Marshall, A., \& Leahey, L. (2003). Contributing factors to muscle weakness in children with cerebral palsy. Developmental Medicine \&
Child Neurology, 45, 542-550. doi:10.1111/j.1469-8749.2003. tb00954.x

Fedrizzi, E., Facchin, P., Marzaroli, M., Pagliano, E., Botteon, G., Percivalle, L., \& Fazzi, E. (2000). Predictors of Independent Walking in Children With Spastic Diplegia. Journal of Child Neurology, 15, 228-234. doi:10.1177/088307380001500405

Ferdjallah, M., Harris, G., Smith, P., \& Wertsch, J. (2002). Analysis of postural control synergies during quiet standing in healthy children and children with cerebral palsy. Clinical Biomechanics, 17, 203-210. doi:10.1016/s0268-0033(01)00121-8

Gallahue, D., \& Ozmun, J. (2005). Understanding Motor Development: Infants, Children, Adolescents, Adults with PowerWeb. New York, NY: McGraw-Hill.

Hadders-Algra, M., Stremmelaar, E., Touwen, B., \& van der Fits, I. (1999). Development of postural adjustments during reaching in infants with CP. Developmental Medicine \& Child Neurology, 41, 766-776. doi:10.1111/j.1469-8749.1999.tb00537.x

Ibrahim, M., Eid, M., \& Moawd, S. (2014). Effect of whole-body vibration on muscle strength, spasticity, and motor performance in spastic diplegic cerebral palsy children. Egyptian Journal of Medical Human Genetics, 15, 173-179. doi:10.1016/j. ejmhg.2014.02.007

Jones, M.W., Morgan, E., Shelton, J., \& Thorogood, C. (2007). Cerebral Palsy: Introduction and Diagnosis. Journal of Pediatric Health Care, 21, 146-152. doi:10.1016/j.pedhc.2006.06.007

Ju, Y.H., Hwang, I.S., \& Cherng, R.J. (2012). Postural Adjustment of Children With Spastic Diplegic Cerebral Palsy During Seated Hand Reaching in Different Directions. Archives of Physical Medicine and Rehabilitation, 93, 471-479. doi:10.1016/j. apmr.2011.10.004

Liao, H.F., Liu, Y.C., Liu, W.Y., \& Lin, Y.T. (2007). Effectiveness of Loaded Sit-to-Stand Resistance Exercise for Children With Mild Spastic Diplegia: A Randomized Clinical Trial. Archives of Physical Medicine and Rehabilitation, 88, 25-31. doi:10.1016/j. apmr.2006.10.006

Lin, J.P. (2003). The Cerebral Palsies: A Physiological Approach. Journal of Neurology, Neurosurgery \& Psychiatry, 74, 23-29. doi:10.1136/jnnp.74.suppl_1.i23

Malaiya, R., McNee, A., Fry, N., Eve, L., Gough, M., \& Shortland, A. (2007). The morphology of the medial gastrocnemius in typically developing children and children with spastic hemiplegic cerebral palsy. Journal of Electromyography and Kinesiology, 17, 657-663. doi:10.1016/j.jelekin.2007.02.009

Marsala, G., \& VanSant, A.F. (1998). Age-Related Differences in Movement Patterns used by Toddlers to rise from a supine position to erect stance. Physical Therapy, 78, 149-159. Retrieved from http://ptjournal.apta.org/

Massion, J. (1998). Postural Control Systems in Developmental Perspective. Neuroscience \& Biobehavioral Reviews, 22, 465-472. doi:10.1016/s0149-7634(97)00031-6

Mewasingh, L., Demil, A., Christiaens, F.J., Missa, A.M., Cheron, G., \& Dan, B. (2002). Motor strategies in standing up in leukomalacic spastic diplegia. Brain and Development, 24, 291-295. doi:10.1016/s0387-7604(02)00059-1

Mewasingh, L., Sékhara, T., Pelc, K., Missa, A.M., Cheron, G., \& Dan, B. (2004). Motor strategies in standing up in children with 
hemiplegia. Pediatric Neurology, 30, 257-261. doi:10.1016/j. pediatrneurol.2003.09.014

Morris, C. (2007). Definition and classification of cerebral palsy: a historical perspective. Developmental Medicine \& Child Neurology, 49, 3-7. doi:10.1111/j.1469-8749.2007.tb12609.x

Palisano, R.J., Hanna, S.E., Rosenbaum, P.L., Russell, D.J., Stephen, D.W., Wood, E.P., ... Galuppi, B.E. (2000). Validation of a model of gross motor function for children with cerebral palsy. Physical Therapy, 80, 974-985. Retrieved from http://ptjournal.apta.org/

Parker, D.F., Carriere, L., Hebestreit, H., Salsberg, A., \& Bar-Or, O. (1993). Muscle Performance and Gross Motor Function of Children with Spastic Cerebral Palsy. Developmental Medicine \& Child Neurology, 35, 17-23. doi:10.1111/j.1469-8749.1993.tb11547.x

Rosenbaum, P., Paneth, N., Leviton, A., Goldstein, M., \& Bax, M. (2007). A report: the definition and classification of cerebral palsy. Developmental Medicine \& Child Neurology, 49, 8-14. doi:10.1111/j.1469-8749.2007.tb12610.x

Scholtes, V., Becher, J., Janssen-Potten, Y., Dekkers, H., Smallenbroek, L., \& Dallmeijer, A. (2012). Effectiveness of functional progressive resistance exercise training on walking ability in children with cerebral palsy: A randomized controlled trial. Research in Developmental Disabilities, 33, 181-188. doi:10.1016/j. ridd.2011.08.026

Silva, D., Pfeifer, L., \& Funayama, C. (2013). Gross Motor Function Classification System Expanded \& Revised: reliability between therapists and parents in Brazil. Brazilian Journal of Physical Therapy, 17, 458-463. doi:10.1590/s1413-35552012005000113

Thompson, N., Stebbins, J., Seniorou, M., \& Newham, D. (2011). Muscle strength and walking ability in Diplegic Cerebral Palsy: Implications for assessment and management. Gait \& Posture, 33, 321-325. doi:10.1016/j.gaitpost.2010.10.091

Van der Heide, J., Begeer, C., Fock, J., Otten, B., Stremmelaar, E., van Eykern, L., \& Hadders-Algra, M. (2004). Postural control during reaching in preterm children with cerebral palsy. Developmental Medicine \& Child Neurology, 46, 253-266. doi:10.1111/j.1469-8749.2004.tb00480.x

VanSant, A.F. (1988a). Rising from a supine position to erect stance. Physical Therapy, 68, 185-192. Retrieved from http://ptjournal. apta.org/content/68/2/185

VanSant, A.F. (1988b). Age Differences in movement patterns used by children to rise from a supine position to erect stance. Physical Therapy, 68, 1330-1339. Retrieved from http://ptjournal.apta.org/

Woollacott, M.H., \& Shumway-Cook, A. (2005). Postural Dysfunction During Standing and Walking in Children With Cerebral Palsy: What are the Underlying Problems and What New Therapies Might
Improve Balance? Neural Plasticity, 12, 211-219. doi:10.1155/ np.2005.211

Yokochi, K. (2001). Gait patterns in children with spastic diplegia and periventricular leukomalacia. Brain and Development, 23, 34-37. doi:10.1016/s0387-7604(00)00200-X

\section{Authors' note}

Elisabete Martins (emartins@essa.pt) is affiliated with Alcoitão School of Health, Portugal

Jorge Fernandes (jorgef@uevora.pt) is affiliated with Department of Sport and Health, Research Center in Sports, Health Sciences and Human Development, Science and Technology School, University of Évora, Évora, Portugal.

Ana Cruz-Ferreira (anacf@uevora.pt) is affiliated with Department of Sport and Health, Research Center in Sports, Health Sciences and Human Development, Science and Technology School, University of Évora, Évora, Portugal.

\section{Corresponding author}

Jorge Fernandes

Colégio Luis Verney - Universidade de Évora, Rua Romão Ramalho, 59, 7000-671 Évora, Portugal.

e-mail: jorgef@uevora.pt

\section{Acknowledgements}

The authors wish to thank the participating children and parents for their support. We also wish to thank PhD Oliveira, PhD Vieira, and all professionals at the Rehabilitation Centre of Cerebral Palsy Calouste Gulbenkian, in Lisbon, Portugal, for their encouragement and support.

Manuscript received on March 2, 2014

Manuscript accepted on June 2, 2015

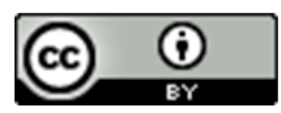

Motriz. The Journal of Physical Education. UNESP. Rio Claro, SP, Brazil - eISSN: 1980-6574 - under a license Creative Commons - Version 3.0 